\title{
PERIODIZAÇÃO DA HISTÓRIA DA EDUCAÇÃO BRASILEIRA: DIMENSÕES TEÓRICAS DAS CONCEPÇÕES DE TEMPO HISTÓRICO
}

\author{
S.B. IVASHITA ${ }^{1}$, J.P.P. COELHO
Universidade Estadual de Londrina ${ }^{1}$
Universidade Estadual de Maringá ${ }^{2}$
sivashita@uel.br ${ }^{1}$ \\ Artigo submetido em 31/08/2018 e aceito em 09/08/2019 \\ DOI: $10.15628 /$ holos.2019.7682
}

\section{RESUMO}

As reflexões referentes às concepções de periodização que fundamentam a escrita da História da Educação são necessárias não só no âmbito do processo de pesquisa como para a prática pedagógica do professor em sala de aula. Sob esta temática, o objetivo das discussões empreendidas deteve-se na análise das articulações existentes entre os pressupostos teórico-metodológicos que orientam a escrita da História da Educação e as suas implicações sobre o processo de periodização nesta área. Para tanto, utilizou-se de pesquisa bibliográfica, tendo como referencial teórico a compreensão de que o tempo se constitui como um conceito plural, elaborado com base nas singularidades que revestem cada época, sociedade e cultura. Conclui-se, que o tempo, por ser um valor norteador da vida humana nos mais diversos modelos de organização social, orienta as ações dos sujeitos sobre o espaço que ocupam. Assim, a periodização da História da Educação deve considerar as múltiplas representações de tempo desenvolvidas em diferentes momentos históricos e em distintos espaços de produção da cultura, expressando rupturas e permanências sociais e culturais historicamente constituídas.

PALAVRAS-CHAVE: História da Educação, Periodização, Teoria da História.

\section{PERIODIZATION OF BRAZILIAN EDUCATION HISTORY: THEORETICAL DIMENSIONS OF HISTORIC TIME CONCEPTIONS}

\begin{abstract}
The reflections regarding the conceptions of periodization which support the writing of the History of Education are necessary not only in the scope of the research process but also for the pedagogical practice of the teacher in the classroom. Based upon the theme previously mentioned, the goal of the discussions was to analyze the articulations between the theoretical and methodological assumptions that guide the writing of the History of Education and its implications on the periodization process of the area mentioned. In order to do this, we used a bibliographical research, having as theoretical reference the understanding that time is a
\end{abstract}

plural concept, elaborated on the basis of the singularities that cover each time, society and culture. It is concluded that time, being a guiding value of human life in the most diverse models of social organization, guide the actions of the subjects on the space they occupy. Thus, the periodization of the history of education must consider the multiple representations of time developed in different historical periods and in different spaces of production of culture, expressing ruptures and social and cultural permanences historically constituted.

KEYWORDS: History of Education, Periodization, History Theory. 


\section{INTRODUÇÃO}

Diante da possibilidade de se conceber a discussão teórica sobre periodização como uma questão menor frente ao conteúdo histórico, é preciso considerar que o entendimento conceitual a respeito do tempo influi nas possibilidades de interpretação dos acontecimentos históricos. Expressão desta premissa é que - diante da amplitude das possibilidades de periodização da história -, na história educacional, o critério de periodização prevalecente, de caráter político-administrativo, tem gerado debates.

É recorrente dentre os estudiosos, (Jorge, 2017; Warde, 1984; Bontempi, 1995), a indagação sobre os eventuais vínculos existentes entre a periodização da história da educação brasileira e os processos políticos e administrativos da nação. Discutem sobre as possibilidades de os marcos temporais da história da educação, quando sustentados por processos históricos externos à dinâmica educacional, promoverem um empobrecimento das possibilidades interpretativas das fontes.

Ainda que o presente trabalho não se atenha propriamente à discussão sobre os eventuais limites e possibilidades advindos dos conceitos temporais circunscritos a critérios políticos e administrativos, esta problemática motivou a elaboração do seguinte questionamento: Como as transformações de caráter teórico metodológico referentes à temporalidade histórica subsidiam as transformações que se processam no campo da pesquisa em História da Educação?

Para estudar o passado, partindo de diferentes compreensões teóricas a respeito da fonte, é necessário que não se perca de vista a dinâmica temporal e espacial que lhe é imanente. Após a seleção das fontes e o estabelecimento de um recorte espaço-temporal, o pesquisador pode ater-se mais detidamente aos limites de seu campo de análise, bem como sobre os meandros pelos quais a pesquisa será conduzida. Porém, embora esse processo se desenvolva na época do historiador, o passado não deve ser posto de forma subordinada aos interesses do presente.

\section{A ESCRITA DA HISTÓRIA DA EDUCAÇÃO: AS CONCEPÇÕES DE PERIODIZAÇÃO}

As preocupações com a periodização, quando se resumem à demarcação da ação do homem no tempo, contribuem para uma perspectiva de história que reduz o passado a "blocos" de conteúdos justapostos. Neste âmbito, a concepção de mudança histórica fica subordinada a fins práticos/didáticos, alheios à dinâmica do próprio passado, que, por vezes, reduz a história, no contexto escolar, à apresentação sucessiva dos conteúdos baseados em marcos temporais mecânicos. Como a história passa a ser desprovida de elementos conceituais que instiguem uma reflexão mais ampla sobre a passagem do tempo, as nuanças entre uma e outra época histórica tendem a ser circunscritas a fatores econômicos, tidos como elementos estruturantes gerais dos processos históricos de mudanças. 
Ainda predomina, nos trabalhos examinados, uma certa tendência de se caminhar pelas fendas já abertas pela historiografia da educação, quando muito acrescentando novos dados, mais do que vasculhando as muitas zonas de sombra nas quais se encontra a história da educação brasileira. No meu entender, isto decorre, principalmente, do fato de que boa parte dos trabalhos não resulta de efetivo interesse na investigação histórica, na efetiva preocupação de historicizar a educação como objeto de análise. Resulta mais de longos recuos no tempo com vistas a encontrar, supostamente, a origem da questão que se está examinando. Ao se realizar esse recuo, tendencialmente, novas investigações históricas não são feitas em profundidade. Disso resulta o reforço às explicações históricas já cristalizadas no pensamento pedagógico (Warde, 1984, p. 5).

Ao trabalhar tal problemática, Nunes (1992, p. 7) argumenta acerca da necessidade de se estabelecer um diálogo com o passado, que "[...] nunca se entrega a nós, mas que nos envia sinais cifrados do seu misterioso desejo, liberar as energias humanas dolorosamente encarceradas no passado". Assim, essas nuanças que a história comporta serão desveladas ao nos voltarmos a ela não como um monumento intocável, mas passível de ser revisitada sob novas perspectivas de análise. Mesmo os temas/objetos/fontes que já foram amplamente trabalhados podem ser revisitados sob a ótica de uma nova perspectiva de análise, podendo afiançar, ante tal insistência, novas investigações até então secundarizadas ou mesmo omitidas.

Entende-se, portanto, que o passado ganha complexidade quando é compreendido pelo historiador como uma época distinta da sua, esforçando-se por entendê-lo mediante a dinâmica interna do próprio passado. Não que a história não tenha ressonância com o presente, todavia qualquer comparação direta entre épocas distintas representa, em última instância, a negação da historicidade da própria História da Educação. O passado é uma época para ser apreendida, investigada, esmiuçada e não repetida, como se houvesse uma ligação direta, de causa e consequência, com o presente.

Daí a importância de o pesquisador ter clareza sobre as distintas concepções de tempo histórico e as maneiras como estas concepções temporais incidem sobre a periodização da história. As delimitações temporais seguem, portanto, orientações teóricas distintas, por vezes, conflitantes. Ao acompanhar o estado de mudanças na concepção de História, constata-se que se instaurou em fins do século XIX:

Depois que a História formalmente se estruturou como um campo de conhecimento, muitos dos historiadores do século XIX estavam preocupados com a ordenação cronológica dos fatos, que era uma das formas possíveis de organizar o conjunto documental, e que acabou sendo a dominante, pois quase sempre permitia a estruturação causal explicativa (Glezer, 2002, p. 23).

Com o intuito de obter uma definição objetiva sobre o conceito de periodização nas bases etimológicas do termo - entendendo que tal assertividade comporta limites ante o amplo lastro 
teórico que o orienta -, encontra-se a ação de dividir a totalidade histórica em distintas sucessões temporais (Almeida, 1988).

Para Saviani (2004), a periodização caracteriza-se como um dos problemas mais complexos e controvertidos da historiografia, tendo em vista que não se trata de um dado empírico, mas de uma questão teórica que o historiador enfrenta ao organizar os dados que lhe permitem explicar o fenômeno investigado. Desse modo, a questão primordial que se apresenta ao processo de periodização está relacionada aos critérios utilizados para organizar os marcos temporais. Este trabalho comporta tanto dimensões subjetivas, relativas às vivências pessoais e profissionais do historiador, quanto critérios "internos" ao objeto estudado, os quais, por serem de caráter teórico e metodológico, dialogam com o tempo imanente à historia.

A História, como expressão da vivência humana no tempo, não é passível, portanto, de ser requisitada como um "testemunho" apresentado ao presente, e sim como perspectiva que, em última instância, parte do próprio tempo do pesquisador. Em outros termos, a história dialoga com o tempo do pesquisador sem, contudo, ir de encontro à organicidade existente entre o sujeito pretérito e a sua época.

Acompanhar uma história é avançar em meio a contingências e incidentes conduzido por uma espera que encontra seu acabamento na conclusão. Compreender a história é compreender como e por que os episódios sucessivos levaram a esta conclusão, que, longe de ser previsível, deve ser aceitável, como congruente com os episódios reunidos (Ricoeur, 1994, p. 127).

Os conhecimentos teóricos produzidos sobre periodização, constantemente problematizados em suas eventuais limitações, subsidiam o olhar do estudioso sobre as fontes. Sob esta ótica, selecionadas as fontes de estudos, é preciso delimitar que "não existe uma divisão absoluta e permanentemente válida do conteúdo da História e que se trata sempre de obter apenas uma divisão mais adequada ao problema que se tem em foco", como enfatizam as palavras de Almeida (1988, p. 115).

O objetivo de periodizar não se reduz, ainda, à necessidade de demarcar temporalmente o homem no tempo, mas compreender as bases que sustentam determinada sociedade no tempo e, de igual modo, como as tensões e fragmentação dessas bases "[...] colaboram a emergência de novas ou reformadas estruturas - o que subsidiam, por fim, uma (re)ordenação das sequências cronológicas" (ALMEIDA, 1988, p. 114).

As significativas transformações na concepção de tempo histórico têm colaborado para que a escrita da história, elaborada sob distintas abordagens teóricas, passasse a expressar novos ritmos narrativos e encadeamentos cronológicos. Esta dinâmica de mudanças, que parte da época do estudioso, estabelece ao historiador a responsabilidade por problematizar tais nuanças nos documentos a serem temporalizados. Como propõe Vidal (2006, p. 26), é “[...] fundamental que dialoguemos muito e constantemente no campo, sem o receio da crítica e dispostos a dividir os achados da pesquisa". 
Há que se considerar que essa percepção a respeito das fontes históricas, como base sobre a qual o historiador deve romper com sentidos hierarquizados sobre o passado, construiuse, no século XX, por meio das leituras realizadas pela escola dos Annales ${ }^{1}$. Para os pensadores pertencentes à escola, o documento/fonte, base para o trabalho do historiador, permanece essencial para a escrita da história, porém deixa de ser concebido como um "monumento", referendado pelos sujeitos de poder. Tudo aquilo que o sujeito produziu intencionalmente, expressando seu registro no tempo, deve ser entendido como referências passíveis de serem usadas para aprofundar o entendimento sobre a história e a cultura humana.

Assume-se, assim, a dimensão subjetiva do tempo que perpassa a história. Administrar esta singularidade histórica é uma tarefa complexa, já que exige, por parte dos estudiosos, respeito tanto ao âmbito da época a que determinado documento ou fonte pertence como dos valores da cultura ou mesmo do espaço geográfico que incide sobre estes documentos.

Para Bloch (2001, p. 17):

[...] perceberam que a história não poderia ser explicada em uma mesma perspectiva temporal, uma vez que havia, especificamente nos sentimentos, temporalidades diferenciadas que implicavam recuos longos para serem compreendidas. Seus estudos levaram ao estabelecimento de três durações simultâneas ao acontecer histórico: a curta duração, que é o tempo do acontecimento; a média duração, na qual se pode perceber a conjuntura na qual o acontecimento se insere; e a longa duração, que possibilita ver as permanências em torno do acontecimento.

A considerar que o tempo é "fluido", que se desdobra sem que os homens possam controlá-lo ou encarcerá-lo, Bloch (2001, p. 52) rejeita a ideia de que a História é a ciência do passado, porque "[...] a própria idéia de que o passado, enquanto tal, possa ser objeto de ciência é absurda". Para ele, o objeto da História é o homem, ou os homens, como prefere enfatizar, ou ainda, o objeto da História são os homens no tempo, tendo em vista que qualquer ciência não pode abstrair do tempo e, da mesma forma, não pode manuseá-lo objetivamente. Contudo há que se datar os homens para que se possa compreendê-los no tempo?

Nenhum historiador, em contrapartida, se contentará em constatar que César levou oito anos para conquistar a Gália e que foram necessários quinze anos a Lutero para que, do ortodoxo noviço de Erfurt, saísse o reformador de Wittenberg. Importa-lhe muito mais atribuir à conquista da Gália seu exato lugar cronológico nas vicissitudes das sociedades européias; e, sem absolutamente negar o que uma crise espiritual como a de irmão Martinho continha de eterno, só julgará ter prestado contas disso depois de ter fixado, com precisão, seu momento na curva dos destinos tanto do homem que foi seu herói como da civilização que teve como atmosfera (Bloch, 2001, p. 55).

\footnotetext{
${ }^{1}$ A partir do século XX construiu-se - por meio das leituras pós-estruturalistas - uma revolução na concepção de tempo, que, até então, era hegemonicamente positivista (CAMBI,1999). A escola dos Annales (fundada por Bloch e Febvre em 1929, primeiramente como uma revista), se estabelece como norteadora desse processo de renovação da ciência histórica.
} 
Quadros cronológicos possuem, portanto, uma margem de oscilação, visto que as demarcações de datas excessivamente rígidas se restringem à necessidade de o sujeito lembrar com maior precisão determinado acontecimento - que, para fins didáticos, é tido como recurso pedagógico eficaz.

Porém, para além dessa finalidade prática da periodização, na pesquisa acadêmica, é preciso que se evidenciem características sociais e culturais para que caracterizem os marcos temporais como uma decisão que, em última instância, extrapolam a ideia de passado como superação mecânica de tudo que o precede. Em outros termos, "não há fracionamento lógico da História que permita isolar completamente um problema numa determinada faixa temporal" (Almeida, 1988, p. 116).

Nunes (1992, p. 12) afirma que, nessa "trepidação" de limites acerca do passado, ele "[...] emerge sempre inacabado, pois o futuro o utiliza de múltiplas maneiras através das gerações que reescrevem as histórias daqueles que as antecederam e com as quais pretendem realizar seu acerto de contas". Ledo engano seria acreditar que a ordem adotada pelos historiadores em suas investigações deva fundamentalmente modelar-se pela ordem dos acontecimentos (Bloch, 2001).

É razoável pensar que, quando o historiador escolhe as questões sobre as quais pretende trabalhar, está realizando um exercício de poder, no qual os limites são dados, entre outros aspectos, "[...] pelo lugar social de onde escreve e pelas práticas institucionais nas quais está mergulhado. É isto que faz da historiografia uma expressiva síntese entre um lugar, um trabalho e um discurso" (Nunes, 1992, p. 13).

Com base nessas reflexões acerca do conceito de tempo histórico que foram desenvolvidas nos limiares do século XIX e XX, faz-se necessário considerar um ponto de convergência: o objeto da história, o fato histórico, é sempre singular. Cabe pensar, destarte, que os fatos históricos são menos sagrados do que se pensa, uma vez que "o fato não é, em história, a base essencial de objetividade, ao mesmo tempo porque os fatos históricos são fabricados e não dados e porque, em história, a objetividade não é a pura submissão aos fatos" (Le Goff, 2003, p. 31).

Periodizar é uma atividade própria do historiador, entendendo que a periodização vai ao encontro da compreensão do "movimento" por intermédio do qual o objeto/sujeito em investigação dialoga com o seu próprio tempo (BARREIRA, 1995). Todavia há que se considerar que a opção por determinada periodização se faz, com frequência, em função dos subsídios teóricos que cumprem demandas do presente, podendo, por vezes, subordinar o tempo passado ao tempo e às exigências que são próprias do estudioso.

Neste âmbito, Le Goff problematiza a relação sempre delicada entre presente e passado, uma vez que:

[...] o passado não deixa de viver e de se tornar presente. Esta longa duração do passado não deve, no entanto, impedir o historiador de se distanciar do passado, uma distância 
reverente, necessária para que o respeite e evite o anacronismo. Se a memória faz parte do jogo de poder, se autoriza manipulações conscientes ou inconscientes, se obedece aos interesses individuais ou coletivos, a história, como todas as ciências, tem como norma a verdade. Os abusos da história só são um fato do historiador, quando este se torna um partidário [...] $(2003$, p. 26).

Diante das discussões sobre a dimensão conceitual da ação do homem no tempo que subsidiam a pesquisa em História da Educação, verificam-se poucas mudanças no campo da periodização da História da Educação, ao menos no que se refere às fontes que fundamentam a presente análise - que reforçam uma escrita da História característica da década de $1980^{2}$. Tratase de um campo/bloco de resistência aos debates empreendidos na área, sobretudo a partir da década de 1990 no Brasil. Os parâmetros de periodização da História da Educação brasileira aparecem, fundamentalmente, não da captação dos momentos propriamente educacionais, mas dos momentos materiais/econômicos do desenvolvimento da sociedade brasileira.

De modo geral, a oficialidade proporcionada pelo Estado oferece ao historiador da educação as bases que o fazem sentir-se mais seguro para realizar seu trabalho: escrever a História da Educação. Ao orientar-se pelos marcos temporais estabelecidos para a História Política do Brasil para a delimitação de seus estudos, o historiador reverencia a centralidade do Estado, concebendo o tempo dos fenômenos educacionais de forma sincronizada ao tempo das práticas políticas institucionalizadas (Bontempi, 1995).

No ano de 1984, Nagle tece críticas aos trabalhos que tomam como periodização, quase sempre, critérios político-administrativos sem o esforço por procurar uma temporalidade acordada com os domínios educacionais. Trata-se de uma "reprodução acrítica das periodizações existentes". Em suas palavras,

[...] são trabalhos em que se procura, sem muitos cuidados, empregar categorias analíticas gerais, para daí 'contextualizar' o estudo, do que tem resultado, também, a mera justaposição de dados (por exemplo, fatores econômicos mais fatores políticos mais fatores sociais mais fatores culturais (Nagle, 1984, p. 27).

A escrita da História da Educação, quando segue marcos extrínsecos ao próprio fazer educacional, descaracteriza o objeto antes mesmo de estudá-lo. Entendemos, como Lopes e Galvão (2001, p. 46), que "a periodização deve ter seus marcos na lógica do próprio objeto que se está pesquisando [...] é preciso que o período escolhido seja significativo para configuração e a explicação daquilo que se está estudando". Almeida (1988, p. 115) reafirma esta ideia argumentando que, "[...] para história política, tais marcos deverão ser necessariamente de caráter político; para a história econômica, marcos econômicos; e, para a história da educação, marcos educacionais".

\footnotetext{
2 Duas dessas tendências são definidas em um artigo escrito por Miriam Warde em 1984, são elas: 1) o objeto em exame determina a periodização; e 2) independentemente do objeto, as periodizações são dadas pelos marcos consagrados na chamada referência 'política'.
} 
É sabido que a área educacional comporta um entrelaçamento com a esfera política, todavia entende-se que, se recortamos o passado sempre pelo mesmo viés - político/econômico - teremos uma explicação no campo educacional que tende a privilegiar o que é externo à história do sistema escolar. Não se quer com isso rechaçar definitivamente os marcos políticos e econômicos, entretanto eles devem ser tomados como balizadores somente se puderem colaborar para o entendimento dos fenômenos educativos.

O que me parece ser a indicação do trato concreto da educação passa pela captação das determinações no próprio âmbito da educação, determinações que se realizam como tal pela mediação do momento político-ideológico. Quero dizer, então, que a educação não é mais uma esfera da realidade social na qual se reflete a "infra-estrutura". A educação é uma das manifestações, em suas peculiaridades, do momento político-ideológico e assim deve ser explicada historicamente no que se refere aos sujeitos nela envolvidos, aos currículos, às instituições que a realizam, à legislação que nela incide e assim por diante (Warde, 1984, p. 3).

Ao olhar para o passado educacional, interpretá-lo e traduzi-lo em forma textual, o historiador da educação insere em sua escrita uma determinada concepção de História, uma identidade teórica que o leva a compreender e a explicar o passado daquela forma, "[...] todo texto histórico traz em si uma teoria, uma determinada concepção de história" (ZANIRATO, 2005, p. 11).

Le Goff (2003) assinala que a concepção de tempo é fundamental para a História e a datação, sendo, neste âmbito, um trabalho fundamental para o exercício do oficio de historiador. Destaca-se que, com base nas reflexões empreendidas, é possível afirmar que não "resgatamos" o passado para entender o presente, o presente é movido por questionamentos inerentes ao seu tempo, que permitem renovar e atualizar o passado todos os dias.

A perda de um bom número de certezas e a renúncia a desmedidas ambições hegemônicas modificaram, profundamente, a situação historiográfica para dar lugar a novas interrogações sobre as noções utilizadas pelos historiadores, que se voltam sobre o passado de sua disciplina, e para os filósofos, que pensaram as categorias da historicidade. O objeto desta obra não visa a preconizar um sistema de história nem pretende esgotar o assunto. Modestamente, ele se quer como um convite à leitura dos historiadores pelos filósofos, e da filosofia da história pelos historiadores. A conjuntura parece favorável a essa nova configuração ou nova aliança entre esses dois domínios conexos porque o historiador de hoje, consciente da singularidade de seu ato de escritura, tende a fazer Clio passar para o outro lado do espelho, numa perspectiva essencialmente reflexiva. Disso resulta um novo imperativo categórico que se expressa pela exigência, de um lado, de uma epistemologia da história concebida como interrogação constante dos conceitos e noções utilizados pelo historiador de ofício e, de outro lado, de uma atenção historiográfica nas análises empreendidas pelo historiador de outrora. (Dosse, 2008, p. 7). 
Assim, entende-se que a História se refere a um conhecimento que parte do tempo do historiador para relacionar-se com o passado. Uma pesquisa não se estabelece de forma aleatória, uma vez que tem uma intencionalidade que é cúmplice das próprias angústias do pesquisador.

Partindo da compreensão de que o passado é analisado não só valendo-se da constante busca pela sua reconstrução, mas também das possibilidades de uma constante reinterpretação, seria leviano acreditar em um passado independente daquele que o historiador constrói (LE GOFF, 2003). Nessa reconstrução permanente do passado, quais questões devem ser priorizadas? Quem decide o que é histórico em cada época? Como afirma Nunes (1992, p. 13): “a leitura que o historiador faz do presente dirige a sua leitura do passado, ambas organizadas em função de problemáticas impostas por certas situações".

\section{CONDSIDERAÇÕES FINAIS}

A periodização está presente, em particular, nas Ciências Humanas, com a finalidade de construir, para efeitos analíticos, uma divisão em períodos ou eras. Afirma-se ainda que a periodização é um processo complexo e importante para as ciências do homem que, para melhor entender e organizar o conhecimento da história da humanidade, é preciso delimitar o sujeito em suas dimensões temporais.

É neste contexto que emerge a necessidade de problematização sobre o tempo por parte do historiador. Se o pesquisador parte da perspectiva de que o passado se desdobrou mediante um processo passível de ser generalizado, ele, na maioria das vezes, acaba por voltar seu olhar apenas para o ordenamento da História com fins organizativos, impossibilitando a ele, por extensão, estabelecer uma análise que alcance o passado em suas particularidades e complexidade.

A tarefa do historiador de ofício ou da educação é questionar, estudar e desnaturalizar as visões cristalizadas sobre o passado. Este é um procedimento necessário para que o passado não seja reconhecido como algo alienado à realidade atual, ou que se considere que sua sobrevivência até nossos dias se deva apenas à sua resistência ao tempo; que se compreenda que ele detém vivacidade própria. Dada a complexidade do fenômeno histórico e a distintas concepções teóricas por meio das quais se olha o passado, periodizar com exatidão os limites dos períodos históricos será sempre uma questão de profícuo debate.

\section{REFERÊNCIAS}

ALMEIDA, M. A. V. (1988). História da educação brasileira - o problema de sua periodização.

Revista Brasileira de Estudos Pedagógicos. Brasília, DF, v. 69, n. 161, p. 112-141, jan/abr. 
BARREIRA, L. C. (1995) História e historiografia: As escritas recentes da História da Educação brasileira (1971-1988). Tese -Universidade Estadual de Campinas, Campinas, SP.

BLOCH, M. (2001). Apologia da História, ou, O ofício do historiador. Rio de Janeiro: Jorge Zahar $\mathrm{Ed}$.

BONTEMPI, B., Jr. (1995) História da educação brasileira: o terreno do consenso. Dissertação Pontifícia Universidade Católica de São Paulo, São Paulo.

CAMBÍ, F. (1999) História da Pedagogia. Tradução de Álvaro Lorencini. São Paulo: Editora UNESP.

DOSSE, F. (2008). A história em migalhas. São Paulo: EDUSC.

GLEZER, R. (2002). Tempo e história. Ciência e Cultura, São Paulo, v. 54, n. 2, p. 23-24.

JORGE, M. Periodização na História da Educação brasileira. Disponível em: <www.histedbr.fae.unicamp.br/acer histedbr/.../GT5.../509.PDF>. Acesso em: 17 fev. 2017.

LE GOFF, J. (2003) História e memória. Tradução Bernardo Leitão et al. 5. ed. Campinas, SP: Editora da UNICAMP.

LOPES, E. M. T.; GALVÃO, A. M. O. (2001). História da Educação. Rio de Janeiro: DP\&A.

NAGLE, J. (1984). História da Educação brasileira: problemas atuais. Em Aberto. Brasília, ano 3, n. 23, set/out.

NUNES, C. (Org.). (1992).O passado sempre presente. São Paulo: Cortez.

SAVIANI, D. (2004).O legado educacional do "longo século XX" brasileira. IN: SAVIANI, Dermeval et. al. O legado educacional do século XX no Brasil. Campinas, SP: Autores Associados.

RICOEUR, P (1994). Tempo e narrativa. Tomo I. São Paulo: Papirus.

VIDAL, D. G. (2006). O campo da História da Educação no Brasil. In: VASCONCELOS, José Geraldo (Org.). História da Educação no Nordeste Brasileiro. Fortaleza: Edições UFC,. p. 15-28.

WARDE, M J. (1984). Anotações para uma historiografia da educação brasileira. Em Aberto. Brasília, ano 3, n. 23, set/out.

ZANIRATO, S. H. (2005). A teoria e a metodologia na escrita histórica. In: MORELI, Ailton José (Org.). Introdução ao estudo da história. Maringá, PR: EDUEM,. p. 11-20.

ZANIRATO, S. H. (2005). Sobre o tempo e os tempos da História. In: MORELI, Ailton José (Org.). Introdução ao estudo da história. Maringá, PR: EDUEM. p. 35-43. 